\title{
Understanding sexual and reproductive health needs of adolescents: Evidence formative study in three districts of lake regions in Tanzania
}

mwifadhi mrisho ( $\sim$ mwifadhi.mrisho@gmail.com )

Ifakara Health Institute

Michaela Mantel

Aga Khan Foundation

Abdunoor M Kabanywanyi

Ifakara Health Institute

Bakar Fakih

Ifakara Health Institute

Manzi Fatuma

Ifakara Health Institute

Sally Mtenga

Ifakara Health Institute

Edna Selestine

Aga Khan Health Services

David Siso

Aga Khan Health Services

Michael Mugerwa

Aga Khan Health Services

Sofia Jadavji

Aga Khan Foundation Canada

Marleen Temmerman

Aga Khan University, Kenya

Hussein Kidanto

Aga Khan University - Tanzania

\section{Research}

Keywords: ASRH, FGDs, HIV/AIDS, menstrual health, sexual consent, prevention of pregnancies,

Posted Date: November 11th, 2021

DOl: https://doi.org/10.21203/rs.3.rs-1049780/v1

License: (c) This work is licensed under a Creative Commons Attribution 4.0 International License. Read Full License 


\section{Abstract \\ Background}

Teenage marriage and adolescent pregnancy present a significant health challenge in the Tanzania. About 36\% of women aged 15-49 are married before the age of 18 , and $32 \%$ of rural adolescents (10-19 years) gave birth, compared with $19 \%$ of urban. In Mwanza region, one third of currently married adolescent and women aged 15-49 experienced unmet need for family planning and had low use of modern contraceptives. Here we present a study that explored the gaps in accessing and utilization of quality adolescent sexual and reproductive health services (ASRH).

\section{Methods}

This was a descriptive and exploratory cross-sectional formative study utilizing multiple qualitative research methods. Purposive sampling was used to select an urban district (Nyamagana), rural district (Magu) and an island (Ukerewe). Sixty-seven IDI and 30 focus group discussions (FGDs) stratified by gender (12 out-of-school, 12 in-school), and ( 3 male, 3 female adults) were purposefully sampled. Vignettes were done with 15-19 years old in-school and out-of-schools boys and girls. An experienced moderator, along with a note-taker, led the discussions while taking notes. The FGDs were recorded using an MP3 voice recorder. Thematic analysis approach was undertaken and data was analysed using NVivo 12 , a qualitative software.

\section{Results}

The identified the most important pressing needs of the adolescents in relation to SRH. Adolescent girls needed specific services such as counselling on menstrual health, sexual consent, HIV/AIDS, and prevention of pregnancies. Sanitary pads during menstrual period were very important pressing need of the adolescent girls. Adolescents both girls and boys preferred to receiving friendly health care services in a respectful manner. Girls mentioned that they would like to receive SRH support from nurses in health facilities, mothers, sisters, aunties and friends. With regards to boys, they preferred to receive the SRH from health care providers followed with their peer's friends. Several obstacles were reported to hinder access to SRHS predominantly among the adolescent girls as compared to the boys. Poor infrastructure tended to impair the privacy at the health facilities, and rarely there were specific buildings to provide friendly adolescent sexual and reproductive health services.

\section{Conclusions}

The strategies to guide delivery of ASRH should involve the inclusion of duty bearers, promotion of friendly health care services where health workers provide services in friendly-manner, provision of ASRH education for awareness creation to adolescents and supportive parents/ care takers.

\section{Plain English Summary}

Adolescents are described as people between the ages of 10 and 19. Around 13 million adolescents live in Tanzania, accounting for $24 \%$ of the total population. Adolescent girls in Mwanza continue to have difficulty getting reproductive health treatments, according to studies. According to the literature, stigma, long wait times, unpleasant healthcare personnel, cultural hurdles, and a lack of privacy in clinics are all obstacles that deter adolescents from obtaining reproductive health care services. 
Instruments were created to collect data on adolescent and reproductive health issues such as adolescents' pressing needs, barriers and enablers to accessing adolescent sexual and reproductive health services in the community, level of privacy for seeking adolescent sexual and reproductive health services offered in health facilities, who and where adolescents want to receive services, and the availability of reproductive health education for adolescents.

The findings suggest that health education or counseling linked to sexual and reproductive health services and care were the most pressing requirements of adolescents in connection to reproductive and sexual health. Adolescent girls required specific treatments such as menstrual health counseling, sexual consent counseling, HIV/AIDS counseling, and pregnancy prevention counseling. During their menstrual periods, adolescent girls had a compelling need for sanitary pads.

In conclusion, the strategies to guide delivery of ASRH should involve the inclusion of duty bearers, promotion of friendly health care services where health workers provide services in friendly-manner, provision of ASRH education for awareness creation to adolescents and supportive parents/ care takers.

\section{Background}

Adolescence which is the time period between 10 and 19 years of age is a critical time period in life during which people undergo extensive biological psychological and social change [1] [2]. The adolescent fertility rate in the low-and middleincome countries is nearly five times the rate in more developed countries [2] [3]. There has been increased importance of adolescent sexual and reproductive health (ASRH) [2]. The global research is calling for more research in this area [4] [5] [6] [7] [8] [2] [9]. The strongest determinants of adolescent health worldwide are structural factors such as national wealth, income inequality and access to education [10]. Improving adolescent health would therefore require improving daily life with families and peers in schools as well as addressing risk factors in social environment and focusing on the factors that are protective across various health outcomes [10].

Tanzania is home to around 13 million adolescents in the age group of $10-19$ years which make up of $24 \%$ of the total population [11]. Thus, adolescents represent a significant number to transform socio-economic development of the country and necessitate knowledge empowerment in this important group [12]. According to Tanzania Demographic and Health Survey (TDHS) data, adolescent fertility rate has increased from 116 to 132 between 2010 and 2015/16 [7]. The adolescent fertility rate is the number of births per 1000 girls aged $15-19$. Teenage pregnancy has also increased by $4 \%$ in the country since 2010 . The TDHS 2015/16 has shown the differences of child bearing rates to exist across the regions ranging from low, 5\% in Mjini Magharib Zanzibar and 6\% in Kilimanjaro to high of 28\% in Mwanza, 45\% in Katavi and 43\%

in Tabora regions. Thirty two percent of adolescents in rural areas are considerably more likely to have begun childbearing as compared of $19 \%$ of their urban counterparts. The report also indicated that only 1 in 10 adolescent girls aged 15-19 were using any modern method of contraceptives.

\section{Adolescent Health In Mwanza}

Adolescent girls are at the highest risk of pregnancy related deaths which is twice as high for girls aged 15-19 and five times higher for girls aged 10-14 compared to women in their 20s [13]. Furthermore, pregnant adolescents are more likely than adults to pursue unsafe abortions [14]. In Tanzania maternal mortality is 556 per 100,000 live births [15], of which $18.5 \%$ are from mothers aged $14-19$ years whereas $31.5 \%$ are from youth between 20-24 years of age [15]. Available evidence show that adolescent girls in Mwanza continue to experience difficulties in accessing reproductive health services [6].

Sexually Transmitted Infections (STIs) including Human Immunodeficiency Virus (HIV/AIDS) remain a great risk for adolescent whereby $40 \%$ of new infections occur among this cohort, condom use outside marriage is as low as $37 \%$ in adolescent girls and 35\% in boys aged 15-19 [7]. Adolescents in Tanzania are at high risk for self-harm and interpersonal 
violence with $50 \%$ of boys and girls aged 13-19 having reported experiencing physical violence at hands of teachers [4]. Apart from the negative health consequences of adolescent pregnancies, girls' access to education and employment opportunities are also minimum. The Ministry of Health, Community Development, Gender, the Elderly and Children (MoHCDGEC) recommends multidisciplinary approach to support adolescent's access to reproductive health information and services and increasing collaboration among governmental, non-governmental and private organizations in promoting youth-friendly services [16] [17]. Studies show that adolescent girls in Mwanza continue to experience difficulties in accessing reproductive health services. The challenges that discouraged adolescent from seeking reproductive health care services includes stigma, long waiting times, unkind healthcare workers, cultural barriers and lack of privacy in the clinics [17]. Thus, the culture is an important factor hindering adolescents to access reproductive health services. Here we present finding of a study to explore the gaps in accessing and utilization of quality ASRH in Mwanza Region, Tanzania.

\section{Methodology}

\section{Design and study areas}

This was a descriptive and exploratory cross-sectional formative study utilizing multiple qualitative research methods. These methods included desk review and mapping of key partners and duty bearers at the onset of study in Mwanza, indepth interviews (IDI) and focus group discussions (FGD), and participatory dialogue and action dissemination at regional levels. Purposive sampling was used to select an urban district (Nyamagana), rural district (Magu) and an island (Ukerewe). Mwanza Region is located in the northwestern section of the country. It is located between latitudes $1^{\circ} 30^{\prime}$ and $3^{\circ} 00^{\prime}$ south of the equator, and longitudes $31^{\circ} 45^{\prime}$ and $34^{\circ} 10^{\prime}$ east of the equator. Kagera Region lies to the west, whereas Shinyanga Region lies to the south and east, and Simiyu lies to the north. The Mwanza region covers a total size of 25,233 square kilometers. Water covers $53.3 \%$ of the land surface, or 13,437 square kilometers, and is dominated by Lake Victoria [18]. As a result, the region is one of the smallest on the Tanzanian mainland in terms of land area. Mwanza accounts for only $3.0 \%$ of the mainland's total area of 942,784 square kilometers. Mwanza Region is divided into seven districts and seven local government authorities, each of which is divided into 24 divisions. Ilemela, Nyamagana, Magu, Ukerewe, Sengerema, Kwimba, and Misungwi are among these districts. As a result of subdividing wards inside townships, municipalities, and cities, divisions are further subdivided into 152 wards, and wards are subsequently subdivided into 458 villages, 3,142 hamlets, and 211 small administrative regions. According to the 2012 National Census Report, Mwanza has a population of 2,772,509 [18]. In this study, we randomly selected two wards from each selected district.

\section{Study Methods, Selection Of Study Participants And Data Collection}

We conducted mapping of key partners and duty bearers at the onset of study in Mwanza region that involved a number of stakeholders (Table 1). All wards in 3 districts of Nyamagana, Magu and Ukerewe, were listed to select one ward from each. Likewise, in each ward, all villages were listed to select one primary school and secondary school. A nearby community within the catchment of the schools was randomly selected to select individuals who participated in IDI and FGDs (as indicated in Table 2 and 3). Health care providers were drawn from health facilities- dispensary, health centre and hospital within the selected ward.

The FGDs were segmented across urban, rural and Island areas of Mwanza region where 10 FGDs were done for each group. FGDs were segmented by gender (girls and boys), age groups (10-14 \& 15-19 years old) and in-schools and outschools adolescents as in Table 3 to ensure intra group homogeneity (Ndyanabangi et al. 2004). Also, it was done with older men (30-49 years old) as well as 3 FGD with older women (30-49 years old). 
Furthermore, participants were informed that discussions would be audio-recorded and will last approximately 60 minutes, and that there would be approximately 6-8 other participants in the discussion.

It is believed that this sample size was sufficient to reach theoretical saturation, the point at which themes are repeated in the data and new information does not appear [19] [20] [21]. Guest et al. (2017) asserts that three focus groups are sufficient to identify $80 \%$ of all themes in the data.

Table 1

Stakeholders Mapping

\begin{tabular}{|lll|}
\hline S/No & Level & Stakeholder Interviewed \\
\hline 1 & Regional & Regional Reproductive and Child Health coordinator (RRCHco). \\
& District & District Medical Officers (DMOs), (3) \\
& DRHCo (3) \\
& DHIS2 coordinators (3) and \\
& Social welfare officers (3). \\
\hline 3 & RCH focal person/ provider (3) \\
\hline Health facility & Maria stopes (FP); \\
at regional and district levels & IMPACT under Aga Khan Development Network partners; \\
& Engender Health; \\
& Tanzania Challenges Initiatives (TCI)-Tupange pamoja; Red-cross \\
& Society and Kizazi Kipya headcount under Pact-Tanzania; \\
& AGPAHI, \\
& ICAP, \\
& Boresha Afya, \\
& JPIEGO; \\
& UNICEF \\
& Kivulini Community Awareness and \\
& PSI-Kuwa mjanja and tulonge Afya programmes. \\
&
\end{tabular}


Table 2

Segmentation of Focus Group Discussion Participants

\begin{tabular}{|c|c|c|c|c|c|c|c|}
\hline \multirow{2}{*}{$\begin{array}{l}\text { Districts } \\
\text { Category }\end{array}$} & & \multicolumn{2}{|c|}{$\begin{array}{l}\text { Nyamagana-Urban } \\
\text { District }\end{array}$} & \multicolumn{2}{|c|}{ Magu-Rural District } & \multicolumn{2}{|c|}{ Ukerewe - Island District } \\
\hline & & $\begin{array}{l}\text { Boys/ } \\
\text { Men }\end{array}$ & $\begin{array}{l}\text { Girls/ } \\
\text { Women }\end{array}$ & $\begin{array}{l}\text { Boys/ } \\
\text { Men }\end{array}$ & $\begin{array}{l}\text { Girls/ } \\
\text { Women }\end{array}$ & $\begin{array}{l}\text { Boys/ } \\
\text { Men }\end{array}$ & $\begin{array}{l}\text { Girls/ } \\
\text { Women }\end{array}$ \\
\hline \multirow{2}{*}{$\begin{array}{l}\text { 10-14 } \\
\text { (Primary school) }\end{array}$} & In-school & 1 & 1 & 1 & 1 & 1 & 1 \\
\hline & $\begin{array}{l}\text { Out- } \\
\text { school }\end{array}$ & 1 & 1 & 1 & 1 & 1 & 1 \\
\hline \multirow{2}{*}{$\begin{array}{l}15-19 \text { (Secondary } \\
\text { School }\end{array}$} & In-school & 1 & 1 & 1 & 1 & 1 & 1 \\
\hline & $\begin{array}{l}\text { Out- } \\
\text { school }\end{array}$ & 1 & 1 & 1 & 1 & 1 & 1 \\
\hline $\begin{array}{l}\text { 30-49 } \\
\text { (Community) }\end{array}$ & Adults & 1 & 1 & 1 & 1 & 1 & 1 \\
\hline
\end{tabular}

Table 3

Key informant on adolescent programs - In-depth Interviews

\begin{tabular}{|c|c|c|c|c|}
\hline \multicolumn{2}{|l|}{ Districts } & \multirow[t]{2}{*}{$\begin{array}{l}\text { Nyamagana-Urban } \\
\text { District }\end{array}$} & \multirow[t]{2}{*}{$\begin{array}{l}\text { Magu-Rural } \\
\text { District }\end{array}$} & \multirow[t]{2}{*}{$\begin{array}{l}\text { Ukerewe - Island } \\
\text { District }\end{array}$} \\
\hline Categories & & & & \\
\hline \multirow[t]{3}{*}{ Health care providers } & Hospital & 1 & 1 & 1 \\
\hline & $\begin{array}{l}\text { Health } \\
\text { Center }\end{array}$ & 1 & 1 & 1 \\
\hline & Dispensary & 1 & 1 & 1 \\
\hline $\begin{array}{l}\text { CBO/NGO working with } \\
\text { adolescent }\end{array}$ & Community & 1 & 1 & 1 \\
\hline \multirow[t]{4}{*}{ Teachers } & Primary & 1 & 1 & 1 \\
\hline & Schools & & & \\
\hline & Secondary & 1 & 1 & 1 \\
\hline & Schools & & & \\
\hline Community Health Workers & & 1 & 1 & 1 \\
\hline \multirow[t]{2}{*}{ Religious leaders } & Islam & 1 & 1 & 1 \\
\hline & Christian & 1 & 1 & 1 \\
\hline \multirow[t]{2}{*}{ Elders } & Male & 1 & 1 & 1 \\
\hline & Female & 1 & 1 & 1 \\
\hline Regional & & 1 & 1 & 1 \\
\hline \multicolumn{5}{|l|}{ Official } \\
\hline District & & 1 & 1 & 1 \\
\hline Official & & & & \\
\hline
\end{tabular}


Both, the in-depth and FGD guide were designed to collect information on adolescent and reproductive health issues such as pressing needs of the adolescents; barriers and enablers to accessing adolescent sexual and reproductive health services within the community; level of privacy for seeking adolescent sexual and reproductive health services offered in health facilities; who and where adolescent want to receive services; availability of reproductive health education available for adolescents; opinion of the person they talk about SRH issues; awareness of adolescent pregnancies; how to improve the quality and utilization of SRH; where do they want to receive services; and what makes a 'good' ASRH provider.

\section{Data Management, Analysis And Ethical Consideration}

Data was captured using audio recording administered by trained enumerators capable of implementing formative research. The analysis team transcribed and translated all audio data recordings from the FGDs and IDIs. After familiarization with the data from the transcripts, a coding framework was developed using thematic approach. All transcripts were typed, saved and exported to the Nvivo 12 software for analysis. Transcripts did not identify any respondents by full name; instead, participants were labeled with a unique code, such as participant 1 , Participant 2 , Participant 3, 4. 5, 6.

The analysis was performed using NVivo 12, a qualitative software program. Specific illustrative quotes from FGD and Indepth interviews were extracted and used in the report. These quotes were not attributed to a specific participant but instead attributed generally.

\section{Ethical and Regulatory Approval}

This study was undertaken by experienced research team which ensured that adequate information about the study was available to national, regional and district health authorities. Meetings of community leaders and district officials from each of the proposed districts in the study area were convened in order to explain the nature of the study. The study was performed in accordance with the protocol, the ethical principles outlined in the Declaration of Helsinki, International Council for Harmonization of Technical Requirements (ICH) Good Clinical Practices (ICH/GCP)[22]. Written informed consent, in accordance with local institutional and national regulatory requirements, was obtained from either an older adolescent (18+ years) and other related adults; parents or legal representative of the minor involved in the study and in addition adolescents who were below 18 years provided an assent [23]. During the study process the study participants were informed that they could refuse participation or withdraw at any point in time without any consequences. Consent of "minor" i.e. age below 18 years were sought from their parents first while an assent was simultaneously obtained from these adolescents. Consent process in non-school attending children was done at home in the community while those from the school attending children, they were informed at school and given consent/assent to send to their parents. In the next day, those who returned with a signed consent/assent were recruited for FGD/vignette session. Considering the sensitive nature of these groups and gender issues of this study, the experienced field workers with track record of doing similar assessment were recruited and trained to implement this study. Likewise, males led the FGDs/vignettes with males and similarly for females. It was expected that the same field workers were capable to handle data collection challenges like recruiting highly sensitive case, (e.g. under age with pregnancy or sexual abuse etc.). As these cases required special attention such as counseling and privacy assurance before data collection was established. The Investigators also ensured that only subjects who gave the informed consent/assent were included in the study. This study was approved by both to IHI, AKU and NIMR with reference number NIMR/HQ/R.8a/Vol.IX/3357.

\section{Results}

We conducted 30 FGD each with 6-8 participants for a total of 180-240 participants and 56 IDI from three districts of Mwanza region as described in Table 4 and 5 that follows. We further conducted vignettes interview sessions among 
adolescents who were in schools and out of schools who were between 15-19 years. Details of their demographic characteristics are in Table 6. The study drew the participants from the communities where different categories of adolescent were identified. For the FGD, the age category for students and out of school was in the range of 10-19 years while the parents were in the age category of 30-49 years old. 
Table 4

Participants socio-demographic characteristics

\begin{tabular}{|c|c|c|c|c|c|c|c|}
\hline District & Ward & FGD type & Sex & $\begin{array}{l}\text { Average } \\
\text { age }\end{array}$ & Education & $\begin{array}{l}\text { Number of } \\
\text { Participants }\end{array}$ & $\begin{array}{l}\text { No. of } \\
\text { FGD }\end{array}$ \\
\hline \multirow[t]{10}{*}{ Nyamagana } & Buhongwa & Boys (10-14) & $M$ & 13 & Primary & 9 & 2 \\
\hline & & & & & $\begin{array}{l}\text { Out of } \\
\text { school }\end{array}$ & 6 & \\
\hline & & Girls (10-14) & $\mathrm{F}$ & 13 & Primary & 7 & 2 \\
\hline & & & & & $\begin{array}{l}\text { Out of } \\
\text { school }\end{array}$ & 5 & \\
\hline & & Boys (15-19) & M & 17 & Secondary & 8 & 2 \\
\hline & & & & & $\begin{array}{l}\text { Out of } \\
\text { school }\end{array}$ & 6 & \\
\hline & & Girls (15-19) & $\mathrm{F}$ & 17 & Secondary & 13 & 2 \\
\hline & & & & & $\begin{array}{l}\text { Out of } \\
\text { school }\end{array}$ & 6 & \\
\hline & & $\begin{array}{l}\text { Parents (30- } \\
49)\end{array}$ & $M$ & 41 & Male & 6 & 1 \\
\hline & & $\begin{array}{l}\text { Parents (30- } \\
49)\end{array}$ & $\mathrm{F}$ & 41 & Female & 6 & 1 \\
\hline \multirow[t]{11}{*}{ Ukerewe } & Nansio & Boys (10-14) & $M$ & 13 & Primary & 8 & 2 \\
\hline & & & & & $\begin{array}{l}\text { Out of } \\
\text { school }\end{array}$ & 7 & \\
\hline & & Girls (10-14) & $\mathrm{F}$ & 14 & Primary & 8 & 2 \\
\hline & & & & & $\begin{array}{l}\text { Out of } \\
\text { school }\end{array}$ & 6 & \\
\hline & & Boys (15-19) & M & 17 & Secondary & 7 & 2 \\
\hline & & & & & $\begin{array}{l}\text { Out of } \\
\text { school }\end{array}$ & 7 & \\
\hline & & Girls(15-19) & $\mathrm{F}$ & 17 & Secondary & 8 & 2 \\
\hline & & & & & $\begin{array}{l}\text { Out of } \\
\text { school }\end{array}$ & 7 & \\
\hline & & Parents (30- & $M$ & 40 & Male & 8 & 1 \\
\hline & & & & & Female & & \\
\hline & & $\begin{array}{l}\text { Parents (30- } \\
49)\end{array}$ & $\mathrm{F}$ & 40 & Female & 6 & 1 \\
\hline \multirow[t]{4}{*}{ Magu } & Shishani & Boys (10-14) & M & 13 & Primary & 6 & 2 \\
\hline & & & & & $\begin{array}{l}\text { Out of } \\
\text { school }\end{array}$ & 5 & \\
\hline & & Girls (10-14) & $\mathrm{F}$ & 13 & Primary & 8 & 2 \\
\hline & & & & & $\begin{array}{l}\text { Out of } \\
\text { school }\end{array}$ & 8 & \\
\hline
\end{tabular}




\begin{tabular}{|c|c|c|c|c|c|c|c|}
\hline District & Ward & FGD type & Sex & $\begin{array}{l}\text { Average } \\
\text { age }\end{array}$ & Education & $\begin{array}{l}\text { Number of } \\
\text { Participants }\end{array}$ & $\begin{array}{l}\text { No. of } \\
\text { FGD }\end{array}$ \\
\hline & & \multirow[t]{2}{*}{ Boys (15-19) } & \multirow[t]{2}{*}{ M } & \multirow[t]{2}{*}{17} & Secondary & 8 & \multirow[t]{2}{*}{2} \\
\hline & & & & & $\begin{array}{l}\text { Out of } \\
\text { school }\end{array}$ & 5 & \\
\hline & & \multirow[t]{2}{*}{ Girls (15-19) } & \multirow[t]{2}{*}{$\mathrm{F}$} & \multirow[t]{2}{*}{16} & Secondary & 8 & \multirow[t]{2}{*}{2} \\
\hline & & & & & $\begin{array}{l}\text { Out of } \\
\text { school }\end{array}$ & 5 & \\
\hline & & $\begin{array}{l}\text { Parents (30- } \\
49)\end{array}$ & M & 39 & & 7 & 1 \\
\hline & & $\begin{array}{l}\text { Parents (30- } \\
49)\end{array}$ & $\mathrm{F}$ & 39 & & 8 & 1 \\
\hline
\end{tabular}


Table 5

IDI participants' socio-demographic characteristics

\begin{tabular}{|c|c|c|c|c|c|c|c|}
\hline District & Ward & IDI type & Sex & $\begin{array}{l}\text { Average } \\
\text { age }\end{array}$ & Education & $\begin{array}{l}\text { Number of } \\
\text { Participants }\end{array}$ & $\begin{array}{l}\text { No. of } \\
\text { IDls }\end{array}$ \\
\hline \multirow[t]{8}{*}{ Nyamagana } & Buhongwa & District level & $M \& F$ & Adult & Unspecified & 5 & 5 \\
\hline & & Teachers & $M \& F$ & Adult & & 2 & 2 \\
\hline & & $\begin{array}{l}\text { Religious } \\
\text { leaders }\end{array}$ & $M$ & Adult & & 2 & 2 \\
\hline & & $\begin{array}{l}\text { Health } \\
\text { providers }\end{array}$ & $\mathrm{F}$ & Adult & & 5 & 4 \\
\hline & & $\mathrm{CHW}$ & $\mathrm{M} \& \mathrm{~F}$ & Adult & & 2 & 2 \\
\hline & & WEO(Mek) & $M$ & Adult & & 1 & 1 \\
\hline & & NGOs & $M$ & Adult & & 2 & 2 \\
\hline & & RRCHCo & $\mathrm{F}$ & Adult & & 1 & 1 \\
\hline \multirow[t]{8}{*}{ Ukerewe } & Nansio & District level & $M \& F$ & Adult & Unspecified & 5 & 5 \\
\hline & & Teachers & $M \& F$ & Adult & & 2 & 2 \\
\hline & & $\begin{array}{l}\text { Religious } \\
\text { leaders }\end{array}$ & $M$ & Adult & & 2 & 2 \\
\hline & & $\begin{array}{l}\text { Health } \\
\text { providers }\end{array}$ & $M \& F$ & Adult & & 4 & 4 \\
\hline & & $\mathrm{CHW}$ & $M \& F$ & Adult & & 2 & 2 \\
\hline & & WEO(Mek) & $M$ & Adult & & 1 & 1 \\
\hline & & NGOs & $M$ & Adult & & 2 & 2 \\
\hline & & WSWo & $\mathrm{F}$ & Adult & & 1 & 1 \\
\hline \multirow[t]{7}{*}{ Magu } & Shishani & District level & $M \& F$ & Adult & Unspecified & 5 & 5 \\
\hline & & Teachers & $M \& F$ & Adult & & 2 & 2 \\
\hline & & $\begin{array}{l}\text { Religious } \\
\text { leaders }\end{array}$ & $M$ & Adult & & 2 & 2 \\
\hline & & $\begin{array}{l}\text { Health } \\
\text { providers }\end{array}$ & $M \& F$ & Adult & & 5 & 4 \\
\hline & & $\mathrm{CHW}$ & $M \& F$ & Adult & & 2 & 2 \\
\hline & & WEO(Mek) & M & Adult & & 1 & 1 \\
\hline & & NGOs & $M$ & Adult & & 2 & 2 \\
\hline
\end{tabular}


Table 6

Social demographic characteristics of participants in vignettes

\begin{tabular}{|c|c|c|c|c|c|c|c|c|}
\hline \multirow{2}{*}{$\begin{array}{l}\text { Details } \\
\text { Ward/Gender/age }\end{array}$} & \multicolumn{2}{|l|}{ Districts } & \multicolumn{2}{|c|}{ Magu - Rural district } & \multicolumn{2}{|c|}{$\begin{array}{l}\text { Nyamagana- Urban } \\
\text { district }\end{array}$} & \multicolumn{2}{|c|}{$\begin{array}{l}\text { Ukerewe-Island } \\
\text { district }\end{array}$} \\
\hline & Education & Gender & Shishani & & Buhongwa & & Nansio & \\
\hline Class level & & & Secondary & Primary & Secondary & Primary & Secondary & Primary \\
\hline \multirow[t]{4}{*}{ Schooling status } & \multirow[t]{2}{*}{ In-school } & Male & 1 & & 1 & & 2 & \\
\hline & & Female & 2 & & 1 & & 2 & \\
\hline & \multirow{2}{*}{$\begin{array}{l}\text { Out-of } \\
\text { school }\end{array}$} & Male & & 1 & & 1 & & \\
\hline & & Female & & & & 1 & & \\
\hline
\end{tabular}

Pressing needs of the adolescents

The most important pressing needs of the adolescent in relation to the reproductive and sexual health included health education or advice related to sexual and reproductive health services and care. Adolescent girls needed specific services such as counselling on menstrual health, sexual consent, HIV/AIDS, and prevention of pregnancies. Sanitary pads during menstrual period were very important pressing need of the adolescent girls. Economic hardship placed majority of the girls in risky position as it was hard to get money from their parents to purchase supplies for their menstrual needs.

There was no difference with regards to the pressing needs across the study districts in regards to girls in school and out of school. However, most of boys in FGDs mentioned that they wanted health education and HIV test while in school. It was also reported that the needs of boys were sometimes overlooked by their parents. Participants in FGDs' sessions mentioned pressing needs for girls as compared to the boys as quoted below: -

"There is a need for the provision of education (advice) and awareness creation on adolescence because many girls do not know about it". FGD, out of school, girls (10-14), Nyamagana district "I think what is needed is to prioritize the needs of these children especially the boys. The boys form a group that is usually forgotten unlike the girls. The father should be educated so they can provide the basic necessities for the boy when they reach adolescents." FGD with female parents, Magu district

"You know these are children and they are not at the age of inserting loops or any other thing as a pregnancy preventive measure. What is needed is to educate the child frequently. When a child starts using contraceptives early, she will get complications when she reaches the right age to conceive. So, you need to warn your child from time to time". FGD with female parents, Magu district

"We shouldn't do sexual intercourse while we are young, we need counselling services when we reach our menstrual period, we are supposed to go to the dispensary so as to be educated on how to protect ourselves while in our menstrual period". FGD, in school girls (10-14), Ukerewe district

"The most important pressing needs here is education". FGD, out of school boys (15-19), Magu

Yes, they are there; when they pass, they tell us to be against childhood pregnancies, also they encourage us not share men and by doing so we will help to reduce spread of HIV/AIDS. FGD, out of school girls (10-14), Magu district

Adolescent SRH support points

Majority of girls in FGDs mentioned a range of people that they would like to receive the services from that included nurses in health facilities, parents, mothers, sisters, aunties and friends. Some of in-school girls (10-14) reported that they

Page $12 / 21$ 
would seek information or guidance from their mothers but were sometimes scared because their parents could sometimes ignore them. The quotes below report that majority of girls would always inform their mothers and friends: -

"The first service I received during my first menstrual circle was from my parents who warned me against talking with men". FGD, out of school girls (10-14), Ukerewe district

"You might go and tell your parent, but she might not listen or sometimes tend to share what you had told her with her neighbors and you might end up being told just go on". FGD, in school girls (10-14), Nyamagana district.

"I talk to my sister because most of the time my mother is busy or sometimes, I talk to my friend". FGD, out of school girls (10-14), Nyamagana district.

"You need to be confident to tell your parents, but you would rather tell a friend that when I woke up yesterday, I found some blood on my bed and a friend would tell my parent. She would explain that I was afraid to tell my mom or Dad so I was ready to help her telling her parents. But on my side when I started my menstrual cycles, I informed my mother and she warned me to be careful and taught me a lot of issues and I am working on the things she was telling me to do". FGD, out of school girls (10-14), Ukerewe district

While some of the participants mentioned that they would like to receive reproductive health information from the media such as radio, television, magazines, and online platforms, majority said they prefer information from the health facility and specifically from health care providers. There was no variation in the responses in relation to 'from whom' they would prefer to get the services in participants of the three visited districts.

"Yes, I can get him easily, because if there is something scared me, I can easily access the health provider". FGD, out of school girls (10-14), Magu district

"Anyone close to me who will solve my problem even my father I will talk to... some daughters are very close to their fathers; they receive great attention to the extent that a girl child does not feel afraid to tell her father about reproductive health issues". FGD, out of school girls (10-14), Nyamagana district

"Hospital is better than home because doctors are knowledgeable and can help you. Doing it at home is not helpful, doctors can help you even with little money they won't let you be humiliated". FGD, Girls, in school (10-14), Ukerewe district

Majority of the respondents mentioned that they were attracted to services which can be easily obtained at health facilities such as condoms, oral contraceptives, implants, counselling and injectable contraceptives. Most of these services are used as contraceptives and perceived to attract adolescent receiving care in the facilities.

Availability of ASRH education

With regards to the availability of education related to $\mathrm{ASRH}$, majority of the participants in FGD sessions reported to have received information from parents, friends, nurses, teachers, religious leaders and older people. The most general knowledge reported was on adolescent pregnancies, sexual abstinence and menstrual health for girls. Some participants said that there was inadequate support received from the parents as they mainly discussed reproductive health issues with their peers or friends. The participants in the FGD sessions and in-depth interviews reported that there was a gap between parents and children especially the male parents. Here are some quotes:

"... most of us receive advice from our mothers as we find it easy to tell them, another thing is, mother knows that her girl child has grown up so she has to instruct her on what to do, for those living with a male parent they find it difficult to explain about their body changes, they have to approach a close friend sometimes at health center". FGD, out of school girls (10-14), Nyamagana district.

Page 13/21 
"For Muslim religion, we provide a lot of teaching about family planning education; for adolescents we ensure that are not part of the peer groups with unwanted behaviors. We control them through giving the Quran teachings; we teach them about family planning by telling them to abstain from sex until she reaches the age of adulthood to get a partner through marriage. We also teach girls on how to protect themselves by covering their bodies and to have self-respect, through this it means she can protect herself and by giving them proper knowledge on reproductive health education. The Quran teaches us a lot of things, since it touches all angles". In-depth interview with religious leader, Magu district.

"We're getting education from school and home; parents are also giving us instructions from engaging in sexual relations under early age". FGD, in-school Boys (15-19), Ukerewe district.

"What I can do is to ask them to abstain from love affairs, to be serious with studying and also stop engaging themselves in risky sexual relationships as they are still young". In-depth interview with religious leader, Nyamagana.

"We always have a teacher who talks about HIV issues for young people and to guide them on the impact and how to protect themselves from it... But about youth health we really don't know maybe as this has come up now as a new chapter maybe we should start looking at it too". In-depth interview with teacher, Nyamagana district.

Reason for the choice of the person to talk to

Majority of those who reported to talk with their parents was due to the fact that parents would provide their adolescents with means of getting sanitary pads and advice. For those who reported to have been talking to their mothers said that they are used to such experience of conversation together and it became easier for them to continue with that relationship. Some of the participants would usually talk to their friends because they were not used to talk with their mothers prior to that moment as quoted: -

"Maybe you start menstrual circle and you have a sister who has passed through that stage you will just talk to your sister. You may realize that going to the parents may not help and going to hospital is not an option as it is not an illness". FGD, out of school girls (10-14), Ukerewe district

"Mother, because we used to have a lot of conversation together". FGD, out of school girls (10-14), Nyamagana district Mothers would educate their girls when they start seeing changes in their bodies or when they start getting menstrual period or when they reach puberty. The mothers were quoted saying: -

"I must sit down with her and tell her that you are now a grown up and you have started menstruation period, you have to be very keen because you can make dirty your clothes with blood when you are in the class or any other place and you won't have any idea that it is happening until somebody else see the mark on the back of your clothes. So, you have to be very careful". FGD with female parent, Magu

"I will also tell her that you have already become an adult, you have to know that when you do sexual intercourse you will get pregnant. When you start sexual intercourse then that means you will start to be called a mother after you get pregnant. You have to know that sexual intercourse is not a good thing."FGD with female parents, Magu

Preferred attributes for ASRH service outlet

With regards to ASRH services delivery attributes, majority of the respondents in FGDs reported that provision of friendly health care services in a respectful manner would make a difference. The age was reported as an important factor for accessing reproductive health care at the health facility. Participants in FGD sessions said that it was difficulty for the under 18 years children to get ASRH from the health facilities. However, the majority of participants recommended putting posters at schools and at the dispensaries to inform adolescent about where to get or access ASRH services. Adolescent

Page 14/21 
reported to have wanted a service provider who is generous; who welcomes you well when you arrive at the facility, who responds and advice you well when you ask a question; the one who cares for you and not disclosing your privacy information to other people.

"age is an important factor because someone can be denied reproductive health services if is under eighteen years". FGD, in school Boys (15-19), Ukerewe district

"I went to hospital seek for condom but they told me that I am still young, Condoms are only provided to those above 18 years old". FGD, in school Boys, Magu district

Overall, the general remarks from adolescents across the surveyed districts was that they wanted service providers to be compassionate, be generous, be gentle, be understandable, respectful, and with humor.

One of the enablers proposed in female FGD was about creating awareness on adolescent and reproductive health. This could be through displaying posters at school as well as offering it through teachers as explained below in quotes below:

"For those services, they can put some posters at the dispensary and at the school area that "children from standard four can come and get education." This is very possible. Even when these posters are put in the school area, the children will be aware and the teachers will be the ones providing this education. So, the children can opt to go the dispensary or the school or both to get sexual reproductive health education". FGD with female parents, Magu district

"I think we need to get reproductive health education from school and specifically from female teachers. If they will ensure privacy and not following us behind, it would be good for us to get reproductive health services from school"FGD with Girls, Magu district

Level of privacy in provision of reproductive health care services

Lack of privacy was another issue reported by participants as an obstacle in accessing reproductive health services in different FGD sessions and IDI. In terms of insufficient privacy in health facilities, the participants reported both, visual and audio privacy must be observed when attended by health care providers. Participants reported that some adolescent cannot express themselves or they may feel shy to ask questions in presence of adults/ parents. The respondents emphasized on separation of adolescents during health education sessions as quoted below:

"I mean, the knowledge provided must be given in different groups because when you provide the knowledge to both parents and adolescents, there is a challenge. When you provide knowledge to all people of different ages some people will feel shy to ask questions. If you want to be understood by someone, let him or her ask questions so that you can explain more. If you mix adolescents with adults/ parents, they won't be free to express themselves" (Key informant, Magu).

"Sometimes nurses at the hospital use to stay near the window, and some people might be there to investigate where are you going, they will just see you from home they decide to follow to know where are you going, they might be listening outside and when they heard you talking about reproductive health issues they come to spread this into the villagers, like we have been telling you this girl is not good she has been affected she is slimming, you will just feel ashamed and just stay at home just crying"FGD, Out of school girls (10-14), Ukerewe district

"Students (forms two to four) were picked and taken to the playing ground located far away from the presence of people. The discussion could not be heard by the third party. The discussion was between girls' students and the reproductive health service providers". FGD, out of school girls (10-14), Nyamagana district

"The doctor didn't talk in public to other people". FGD, out of school girls, Magu district

Page 15/21 
"Because of presence of equipment for providing services, also the area prevents you from other people to know who has entered the room to receive services". FGD, out of school girls (10-14), Magu district

\section{Discussion}

This study has confirmed important gaps in accessing and utilization of quality adolescent sexual and reproductive health services [24] [25]. Among the reported needs of the adolescents included health education and advice related to sexual and reproductive health services. Also much needed were specific services such counselling on menstrual period, how girls can protect themselves against men's temptation, HIV/AIDS, and how to avoid adolescent pregnancies as reported elsewhere [25]. Sanitary pads during menstrual period were reported to be important pressing need of the adolescent's girls. This is similar to what has been reported elsewhere [26].

The needs of boys were sometimes overlooked by their parents, as it was thought that boys did not have visible needs compared to girls. Adolescent boys as it is for girls needed trainings on stages in growth and protection against HIV. Access to available ASRH information was articulated as one of the pressing needs for adolescents yet lack of reliable source of ASRH information platforms and inadequate curricular at school was reported profound across the study districts. The minor adolescents were the most vulnerable of access to ASRH information as they had limited access to the sole active source of necessary information, the health facility. Given their age, it was uncommon for them to seek ASRH and this is also due to poor perception of and low knowledge on ASRH needs by health care providers. Adolescents who are out-of-school environment were also deprived of access to necessary ASRH information. In this group the deprivation was due to their natural inability to be at school where some limited sexuality education is provided and sometimes backed up by organized youth clubs for life skills development activities, only school goers attend these clubs. Access to contraceptives, condoms, and pain killers during menses with excessive menstrual bleeding and the necessary knowledge and skills to negotiate and use contraception remain a challenge for adolescents in Mwanza region. Similar phenomena were recently reported elsewhere in the LMICs [27].

With regard to the place of receiving care, majority of the adolescent boys and girls preferred to receive reproductive care from the health facility. There was no variation on the responses 'from whom' they would prefer to get the services between the three visited districts. In urban setting, some girls talked to their father regarding reproductive health issues contrary to the rural girls. The services that were provided in health facilities like condoms, oral medicine, implants, counselling and injectable very much attracted adolescents, of which mostly were perceived as contraceptives for the adults.

The study highlighted the range of support preferred by majority of participants. For example, girls participants in most FGDs stated that they would like to receive ASRH services from nurses in health facilities, followed by parents, mothers, sisters, aunties and friends. It is important to consider this preference and equip the health facilities with trained providers who can offer friendly services to the adolescents. Some of in-school girls (10-14) reported that they would seek information or guidance from their mothers but were sometimes scared because their parents could sometimes ignore them. It is important to consider this important need of the adolescents. In this study, we couldn't find the differences between the in-school and ot-of-school variation in terms of seeking ARHS as noted from other studies [28]. Health care providers and parents should also be educated to offer good care to the adolescents as they are also in the list of preference. This is similar to what was reported by Laski and colleagues, 2015 [26].

The adolescents support for ASRH was gendered oriented. Girls were mainly supported by nurses in health facilities and their female family members' mothers followed by sisters, aunties and other female friends. Some of in-school girls (1014) reported that they would inform their mothers about important issues related to menstrual health but sometimes were scared as they felt ignored by parents. The issue of fear and associated taboos in menstrual health has been reported elsewhere in the similar settings [29]. For the boys, they mainly reported to share the information related to reproductive

Page $16 / 21$ 
health with their peers' friend and rarely parents. The media was also very important for few adolescents to receive information such as radio, television, magazines, and online platforms. To sum up, majority of the adolescents received general knowledge on ASRH from parents, friends, nurses, teachers, religious leaders and older people. Mostly needed ASRH was on adolescent pregnancies, sexual abstinence and menstrual health for girls. The specific ASRH knowledge and support was inadequately received from the parents but mainly discussed with their peers or friends. There was clear gap on ASRH between parents and children especially the male parents.

Majority of girls in FGDs mentioned a range of people that they would like to receive the services from that including nurses in health facilities, parents, mothers, sisters, aunties and friends. Some of in-school girls (10-14) reported that they would seek information or guidance from their mothers but were sometimes scared because their parents could sometimes ignore them. While some of the participants mentioned that they would like to receive reproductive health information from the media such as radio, television, magazines, and online platforms, majority said they prefer information from the health facility and specifically from health care providers. There was no variation in the responses in relation to 'from whom' they would prefer to get the services in participants of the three visited districts. It is therefore important to consider adolescent support points of communication in order to design appropriate messages related to $\mathrm{SRH}$. In this study we also found important attributes preferred by majority of the respondents in FGDs. Adolescents reported that provision of friendly health care services in a respectful manner as a motivating factor for seeking health care from health facility. This finding is inline with what have been reported elsewhere [25, 30].

In terms of ASRH service preferences, adolescent appreciated health providers that were compassionate, generous, gentle, understandable, respectful and with humor. Young age should not deter provision of ASRH. Adolescents wanted to be informed about SRH using posters at the service place and at school area as important in creating awareness for and get enlightened. Peer coaching whereby capacitated and knowledgeable age mates take the role to coach colleague was appreciated by adolescents as good practice in access to right ASRH information.

Friendly health care services tailored for adolescents and not linked to routine reproductive maternal and child health clinics where health providers listen and use the proper language were found to be enablers to access reproductive health services. However, limiting access for the minors (10-14 years) was an obstacle in accessing reproductive health services from the health facilities. Providers of similar gender of adolescents who are also young were perceived the best enablers for ASRH access by all adolescents from various gender and age groups in all study districts - rural, urban and island. In Tanzania, insufficient youth-friendly health care may have a significant role in the high frequency of risky sexual practices and their repercussions. Efforts should be aimed at establishing service delivery sites that are designed to make health services more accessible and appealing to teenagers, so that they are more likely to be able to and willing to receive the care they require [31].

Choosing a person to talk to on SRH was a major issue. Mothers were specifically very important in talking to their girls such that the conversation together became easier and strengthened that relationship. This was initiated when changes started in their bodies or when girls start getting menstrual period or when they reach puberty. However, girls also reached out to friends and peers as second-best alternative to mothers in discussion regarding $\mathrm{SRH}$. It is important to consider this important need of the adolescents. In rare cases, fathers were approached so that to be provided means of getting sanitary pads and advice. For boys as we said, they rarely receive family support but are outward looking, and this was evident from various methods - in FGD and in vignette. Thus, strengthening facilitation pool for adolescent in various platform is very important - the teachers, religious leaders and peers.

For in-school adolescent, youth clubs or associations were very important compared to out-of-school ones where they had no platform to discuss their issues. Most club groups were formed by NGOs that conducted youth seminars on various issues including SRH. Teacher were also able to mobilize students to discuss issue of HIV and other SRH issues as

Page $17 / 21$ 
reported by teachers and district officials. The groups focused on providing education by teaching practical skills and through competitions.

\section{Conclusion}

The strategies to guide delivery of ASRH should involve the inclusion of duty bearers, promotion of friendly health care services where health workers provide services in friendly-manner, provision of ASRH education for awareness creation to adolescents and supportive parents/ care takers. Effective interventions and best practice models are those that include multiple components that stimulate effective supply and demand of ASRH. They should promote awareness education and comprehensive approaches targeting the adolescents themselves and the key reference persons including parents, health care providers, teachers and religious leaders. The policies and legislations for ASRH need to cater for multisectoral needy of health and education and encourage stakeholders' involvement.

\section{Abbreviations}

AIDS-Acquired Immune Deficiency Syndrome

ASRH-adolescent sexual and reproductive health services

CBO-Community Based Organisation

DMOs-District Medical Officers

DHIS2-District Health Information Software

DRHCo-District Reproductive Health Coordinator

FGD-Focus Group Discussion

GCP Good Clinical Practices

HIV-Human Immunodeficiency Virus

ICH-International Council for Harmonization of Technical Requirements

IDI-In-depth Interview

IHI-Ifakara Health institute

IMPACT- Improving Access to Maternal and Newborn Health in Tanzania

MoHCDGEC-Ministry of Health, Community Development, Gender, the Elderly and Children

NGO-Non-Governmental Organisations

Sexually Transmitted Infections (STI)

SRH-Sexual Reproductive Health

RCH-Reproductive Child Health

RRCHco-Regional Reproductive and Child Health coordinator

Page $18 / 21$ 
TCI-Tanzania Challenges Initiatives

TDHS- Tanzania Demographic and Health Survey

\section{Declarations}

\section{Ethics approval and consent to participate}

This study was approved by both to IHI, AKU and NIMR with reference number NIMR/HQ/R.8a/Vol.IX/3357.

\section{Consent for publication}

Not applicable

\section{Availability of data and materials}

The datasets generated during and/or analysed during the current study are available in the saver of Ifakara Health Institute and can be available upon request.

\section{Competing interests}

The authors declare that they have no competing interests

\section{Funding}

Research reported in this dissertation was supported by the Aga Khan Foundation Tanzania. However, the content of this work is solely the responsibility of the authors and does not necessarily represent the official views of the Aga Khan Foundation.

\section{Authors' contributions}

MM-1 collected, analyzed, wrote the first draft of the manuscript and interpreted the data. MM-5, AMK, BF, FM, SM, ES, DS, MM-3, SJ, MT and HK supervised data collection, commented on the analysis and interpretation of the data, and were major contributors in writing the manuscript. All authors read and approved the final manuscript.

\section{Acknowledgements}

We wish to acknowledge Ifakara Health Institute, which has contributed to the successful execution of this work. Secondly, we are indebted to the participants, data collectors, and district officials of three districts of Mwanza regions who participated in this study. Finally, we are grateful to Aga Khan Foundation-Tanzania for funding this work.

\section{References}

1. Dick, B. and B.J. Ferguson, Health for the world's adolescents: a second chance in the second decade. Journal of Adolescent Health, 2015. 56(1): p. 3-6.

2. $\quad$ Rankin, K., et al., Adolescent sexual and reproductive health: an evidence gap map. 2016. 5.

3. Rosen, J.E. and R. Levine, Background Paper: Mainstreaming Adolescent Girls into Indicators of Health Systems Strengthening. 2010.

4. UNICEF, Adolescence in Tanzania. Dar es Salaam: United Nations Children's Fund Tanzania, 2011. 
5. Organization, W.H., Assessment of barriers to accessing health services for disadvantaged adolescents in Tanzania, 2019

6. Chandra-Mouli, V., et al., Standardizing and scaling up quality adolescent friendly health services in Tanzania. 2013. 13(1): p. 579.

7. Ministry of Health, C.D., Gender, Elderly, M.o.H. Children, National Bureau of Statistics, Office of the Chief Government Statistician, and ICF, Tanzania Demographic and Health Survey and Malaria Indicator Survey (TDHS-MIS) 2015-16, 2016, MoHCDGEC, MoH, NBS, OCGS, and ICF Dar es Salaam, Tanzania, and Rockville.

8. Kuruvilla, S., et al., The Global strategy for women's, children's and adolescents' health (2016-2030): a roadmap based on evidence and country experience. 2016. 94(5): p. 398.

9. UNFPA-Tanzania, Fact sheet: Teenager pregnancy.

10. Viner, R.M., et al., Adolescence and the social determinants of health. 2012. 379(9826): p. 1641-1652.

11. World Health Organization, Handbook for conducting an adolescent health services barriers assessment ( AHSBA) with a focus on disadvantaged adolescents: knowing which adolescents are being left behind on the path to universal health coverage, and why. 2019.

12. MOHCDGEC, NATIONAL ADOLESCENT HEALTH AND DEVELOPMENT STRATEGY2018 -2022, R.a.c.h. section, Editor 2018.

13. WHO, Global health estimates 2015: deaths by cause, age, sex, by country and by region, 2000-2015. 2016.

14. Jones, J. and J.J.N.Y.W.s.R.C.R.d.h.w.o.r.d. Podkul, Forced from home: The lost boys and girls of Central America. 2012.

15. Demographic, T., health survey and malaria indicator survey (TDHS-MIS) 2015-16. Dar es Salaam/Tanzania, 2016.

16. Aarø, L.E., et al., Promoting sexual and reproductive health in early adolescence in South Africa and Tanzania: Development of a theory-and evidence-based intervention programme. 2006. 34(2): p. 150-158.

17. Hokororo, A., et al., Barriers to access reproductive health care for pregnant adolescent girls: a qualitative study in Tanzania. 2015. 104(12): p. 1291-1297.

18. THE UNITED REPUBLIC OF TANZANIA PRIME MINISTER'S OFFICE REGIONAL ADMINISTRATION AND LOCAL GOVERNMENT, MWANZA REGION REGIONAL SECRETARIAT STRATEGIC PLAN 2014 - 2017. 2014-17.

19. Glasser, B. and A.J.N.Y. Strauss, The Discovery of Grounded Theory: Strategies for Qualitative Research Adline De Gruyter. 1967.

20. Francis, J.J., et al., What is an adequate sample size? Operationalising data saturation for theory-based interview studies. 2010. 25(10): p. 1229-1245.

21. Guest, G., E. Namey, and K.J.F.m. McKenna, How many focus groups are enough? Building an evidence base for nonprobability sample sizes. 2017. 29(1): p. 3-22.

22. Bhuiyan, P. and N. Rege, ICH Harmonised Tripartite Guideline: guideline for good clinical practice. 2001. 
23. Mashalla, Y.J.S., Shija, J.K., Kitua, A.Y., Mwaikambo, E., Kohi, Y.M., Ndossi, G.D., Malecela, M., Mboera, L.E.G. , Guidelines of Ethics for Health Research in Tanzania. Tanzania National Health Research Forum. 2009.

24. UNICEF, Adolescence in Tanzania. Dar es Salaam: United Nations Children's Fund Tanzania, 2011.

25. Atuyambe, L.M., et al., Understanding sexual and reproductive health needs of adolescents: evidence from a formative evaluation in Wakiso district, Uganda. Reproductive health, 2015. 12(1): p. 1-10.

26. Laski, L., Realising the health and wellbeing of adolescents. bmj, 2015. 351.

27. Cartwright, A.F., et al., Access to family planning for youth: perspectives of young family planning leaders from 40 countries. Gates Open Res, 2019. 3: p. 1513.

28. Ndyanabangi, B., W. Kipp, and H.-J. Diesfeld, Reproductive health behaviour among in-school and out-of-school youth in Kabarole District, Uganda. African journal of reproductive health, 2004: p. 55-67.

29. Newton-Levinson, A., J.S. Leichliter, and V. Chandra-Mouli, Help and Care Seeking for Sexually Transmitted Infections Among Youth in Low- and Middle-Income Countries. Sex Transm Dis, 2017. 44(6): p. 319-328.

30. Damian, R.S., H. Zakumumpa, and S. Fonn, Youth underrepresentation as a barrier to sexual and reproductive healthcare access in Kasulu district, Tanzania: A qualitative thematic analysis. International journal of public health, 2020. 65(4): p. 391-398.

31. Nkata, H., R. Teixeira, and H. Barros, A scoping review on sexual and reproductive health behaviors among Tanzanian adolescents. Public health reviews, 2019. 40(1): p. 1-15. 